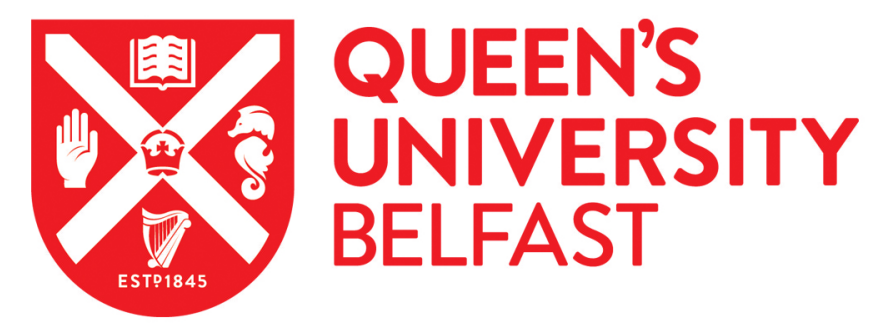

\title{
Biomimetic accumulation of PAHs from soils by triolein-embedded cellulose acetate membranes (TECAMs) to estimate their bioavailability
}

Tao, Y. Q., Zhang, S. Z., Wang, Z. J., Ke, R. H., Shan, X. Q., \& Christie, P. (2008). Biomimetic accumulation of PAHs from soils by triolein-embedded cellulose acetate membranes (TECAMs) to estimate their bioavailability. Water Research, 42(3), 754-762. https://doi.org/10.1016/j.watres.2007.08.006

Published in:

Water Research

Queen's University Belfast - Research Portal:

Link to publication record in Queen's University Belfast Research Portal

\section{General rights}

Copyright for the publications made accessible via the Queen's University Belfast Research Portal is retained by the author(s) and / or other copyright owners and it is a condition of accessing these publications that users recognise and abide by the legal requirements associated with these rights.

Take down policy

The Research Portal is Queen's institutional repository that provides access to Queen's research output. Every effort has been made to ensure that content in the Research Portal does not infringe any person's rights, or applicable UK laws. If you discover content in the Research Portal that you believe breaches copyright or violates any law, please contact openaccess@qub.ac.uk. 


\title{
Biomimetic accumulation of PAHs from soils by triolein-embedded cellulose acetate membranes (TECAMs) to estimate their bioavailability
}

\author{
Yuqiang Tao ${ }^{a}$, Shuzhen Zhang ${ }^{a, *}$, Zijian Wang ${ }^{a}$, Runhui Ke ${ }^{a}$, \\ Xiao-quan Shan ${ }^{a}$, Peter Christie ${ }^{b}$
}


Chinese Academy of Sciences, P.O. Box 2871, Beijing 100085, China

${ }^{\mathrm{b}}$ Agricultural and Environmental Science Department, Queen's University Belfast, Newforge Lane, Belfast BT9 5PX, UK

\section{A R T I C L E I N F O}

Article history:

Received 15 May 2007

Received in revised form

6 August 2007

Accepted 7 August 2007

Available online 11 August 2007

Keywords:

TECAMs

SPMDs

Bioavailability

PAHs

Earthworms

Soils

\begin{abstract}
A B S T R A C T
A new passive sampling device (PSD), a triolein-embedded cellulose acetate membrane (TECAM), was used to biomimetically accumulate naphthalene, phenanthrene, pyrene and benzo[a]pyrene from ten spiked soils and a soil spiked with different concentrations of these polycyclic aromatic hydrocarbons (PAHs). TECAM exposure conditions were optimized. The quantities of PAHs accumulated by TECAMs were positively and linearly related to their concentrations in the soil. PAHs accumulated by TECAMs were negatively related to soil organic matter (SOM) and positively related to the dissolved organic carbon (DOC) according to the results obtained from ten spiked soils. Aging time (1-150 days) had a significant effect on accumulation of PAHs by TECAMs. A good linear relationship $\left(R^{2}=0.970-0.993\right)$ was observed between TECAM-accumulated PAHs and PAHs accumulated by earthworms (Eisenia andrei). The data indicate that TECAM represents a useful surrogate to estimate the bioavailability of PAHs and perhaps other hydrophobic organic contaminants (HOCs) in soils.
\end{abstract}

(c) 2007 Elsevier Ltd. All rights reserved.

\section{Introduction}

Hydrophobic organic contaminants (HOCs) such as polycyclic aromatic hydrocarbons (PAHs) in soils are a major issue of concern. Bioavailability is an important factor in risk assessment and depends on soil characteristics such as $\mathrm{pH}$, organic matter content and moisture, chemical properties of the contaminants and aging time of the contaminants in soil (Alexander, 2000).

Several approaches have been developed to estimate bioavailability of HOCs in soils. The assessment may be performed by direct exposure of various organisms to soils with subsequent determination of contaminant uptake or degradation (Semple et al., 2003). However, biological assays are often time-consuming and expensive and lack the precision required for regulatory purposes (Liste and Alexander, 2002). Chemical extraction methods have been proposed and applied to measure the bioavailable fraction of HOCs in soils (Alexander, 1995; Kelsey et al., 1997; Tang et al., 2002). Harsh, vigorous extraction procedures may remove a large proportion of a contaminant from soils, resulting in an overestimation of bioavailability (Reid et al., 2000a; Tang et al., 2002). Some authors (Kelsey et al., 1997; Reid et al., 2000a,b; Liste and Alexander, 2002) have proposed the use of more gentle and selective extractants, such as ethanol, ethanolwater, methanol-water, n-butanol, hexane, cyclodextrin or

*Corresponding author. Tel.: +8610 62849683; fax: +861062923563.

E-mail address: szzhang@rcees.ac.cn (S. Zhang).

0043-1354/\$- see front matter ๔ 2007 Elsevier Ltd. All rights reserved. doi:10.1016/j.watres.2007.08.006 
organic acids, to predict bioavailability of HOCs in soils. However, it is unrealistic to expect to predict bioavailability of different HOCs using a range of sorbents under a wide range of conditions simply by using a single chemical extractant (Alexander, 2000; Reid et al., 2000a). Furthermore, chemical extraction methods are usually time-consuming, expensive and of relatively low precision.

Passive sampling devices (PSDs) such as semi-permeable membrane devices (SPMDs) (Huckins et al., 1990), solid-phase microextraction (SPME) (Conder et al., 2003; Van Der Wal et al., 2004) and $C_{18}$ sampling bags (Awata et al., 2000) or disks (Krauss and Wilcke, 2001), have been used to measure bioavailability of organic contaminants in soils and sediments. The triolein-containing SPMDs developed by Huckins et al. (1990) are commonly used for sampling HOCs in water (Huckins et al., 1999), air (Söderström et al., 2005) and sediments (Rantalainen et al., 2000). SPMDs have attracted great interest as potential biological surrogates to evaluate the availability of chemicals to organisms and have been successfully applied to estimate bioavailability of HOCs to aquatic organisms (e.g. fishes and mussels) (Verweij et al., 2004; Gourlay et al., 2005). However, their application in terrestrial environments (including soils) is relatively new and very limited applications of SPMDs have been reported to sample or monitor HOCs in soils (Rantalainen et al., 1998; Ahn et al., 2005). Although SPMEs have been more widely used to predict bioavailability of HOCs in soils than other PSDs, disadvantages have been pointed out related to their fiber stability (physical or chemical) and sensitivity (Hernandez et al., 2000). $C_{18}$ sampling bags (Awata et al., 2000) or disks (Krauss and Wilcke, 2001) have also been reported to measure bioavailability of organic contaminants in soil, but the sampling was conducted at $40{ }^{\circ} \mathrm{C}$ for 15 days. Moreover, since the volume of the disk and the corresponding volume of the hydrophobic $\mathrm{C}_{18}$-material are much larger than that of SPMD or SPME fiber, when it is used in soils a high soil water holding capacity is required to avoid depletion, which exceeds the normal moisture content of field soil (Verhaar et al., 1995).

A new type of composite membrane, the triolein-embedded cellulose acetate membrane (TECAM) in which triolein drops are embedded in the matrix of cellulose acetate polymers, was recently developed by Wang and co-workers (Xu et al., 2005). TECAMs have been successfully used to sample HOCs in water and have shown a much shorter uptake equilibrium time than SPMDs made of low-density polyethylene membranes (Xu et al., 2005; Ke et al., 2006) because cellulose dialysis membranes have hydrophilic hydroxyl groups.

In the present study, TECAMs were used to biomimetically accumulate naphthalene (Nap), phenanthrene (Phe), pyrene (Pyr) and benzo[a]pyrene (Bap) from ten spiked soils and a spiked soil with different concentrations of these PAHs. TECAM exposure conditions were optimized. Relationships between the accumulation of PAHs by TECAMs and concentrations and aging time of the PAHs in the soil and soil properties were investigated. In addition, accumulation of PAHs by TECAMs and earthworms (Eisenia andrei) were compared to evaluate the possibility of using TECAM as a surrogate to estimate bioavailability of PAHs in soils.

\section{Materials and methods}

\subsection{Chemicals, reagents, TECAMs and earthworms}

Nap, Phe, Pyr and BaP of $>99 \%$ purity were purchased from Acros Organics (New Jersey, USA) and used for identification and quantification. All solvents used, i.e. n-hexane, dichloromethane and methanol, were of HPLC grade.

TECAMs were prepared according to Xu et al. (2005). They were made of cellulose acetate ( $17.5 \mathrm{wt} \%$, Eastman, USA), acetone (69wt\%), 1,4-dioxane (10wt\%), anhydrous magnesium perchlorate (2wt\%) and triolein (1.5 wt\%, Sigma, USA). All the membranes were kept in distilled water before use.

The earthworm species used was Eisenia andrei. The individuals were of similar weight (fresh weight about $0.15-0.20 \mathrm{~g}$ ) and size (about $4-5 \mathrm{~cm}$ ) and had $79 \pm 6.1 \mathrm{wt} \%$ moisture content and a lipid content of $3.08 \pm 0.61 \%$ (mean $\pm S D, n=15$ ) on a dry-weight basis. They were allowed to acclimatize to laboratory conditions for at least 2 weeks and were analyzed for PAH residues before use.

\subsection{Soil preparation}

Samples of the ten soils used in this study were collected from the top $20 \mathrm{~cm}$ of the soil profiles of agricultural fields in different provinces or cities in China. Each soil sample was air-dried, passed through a $2 \mathrm{~mm}$ sieve and sterilized by $\gamma$ irradiation from a ${ }^{60} \mathrm{Co}$ source. Soil organic matter (SOM) content was determined using the Walkley-Black method (Nelson and Sommers, 1982). Dissolved organic carbon (DOC) was determined with a total organic carbon analyzer (Phoenix, 8000, Tekmar-Dohrmann Co., USA) after shaking $1 \mathrm{~g}$ of soil in $30 \mathrm{ml}$ deionized water for $24 \mathrm{~h}$, centrifuging at $7000 \mathrm{~g}$ for $20 \mathrm{~min}$ and filtering with a $0.45 \mu \mathrm{m}$ cellulose nitrate membrane. Selected soil properties are listed in Table 1.

Beijing soil was spiked with Nap, Phe, Pyr and BaP in acetone to produce a series of initial concentrations $(0.2,0.5$, 2.0, 5.0 and $10.0 \mu \mathrm{gg}^{-1}$ ), and the other nine soils were spiked with one concentration of $5 \mu \mathrm{gg}^{-1}$ only. Each spiked soil was mixed thoroughly to distribute the chemicals uniformly and to allow the solvent to evaporate and then stored in brown glass containers at room temperature for aging.

\subsection{TECAM biomimetic accumulation}

Spiked soil $(10 \mathrm{~g})$ was placed in a $100 \mathrm{ml}$ beaker. A piece of TECAM $\left(2 \times 3 \mathrm{~cm}\right.$, triolein $4.84 \mathrm{wt} \%$ dry weight, $2.5 \mathrm{mg} \mathrm{cm}^{-2}$ dry weight) was embedded in the soil and $3 \mathrm{ml}$ deionized water was added dropwise to the beaker. The beaker was covered with polyethylene membrane to prevent moisture loss and then kept in the dark at room temperature. Three replicates were set up for each PAH concentration or each soil. TECAMs were collected from the beakers after 21 days. The schematic diagram of TECAM accumulation of PAHs from soil is shown in Fig. 1.

\subsection{Accumulation of PAHs by earthworms}

Three active earthworms acclimatized to laboratory conditions for at least 2 weeks were transferred to a $500 \mathrm{ml}$ glass 
Table 1 - Selected physicochemical properties of the soils and the concentrations of PAHs in soils after incubation for 3 months

\begin{tabular}{|c|c|c|c|c|c|c|c|c|}
\hline Soil & Classification & $\operatorname{Nap}\left(\mu g g^{-1}\right)$ & Phe $\left(\mu g g^{-1}\right)$ & Pyr $\left(\mu g g^{-1}\right)$ & $\mathrm{BaP}\left(\mu g g^{-1}\right)$ & OM (\%) & $\mathrm{DOC}\left(\mu g g^{-1}\right)$ & $\mathrm{pH}$ \\
\hline Kunming & Ultisol & 2.80 & 4.37 & 4.33 & 3.90 & 2.87 & 325.0 & 7.12 \\
\hline Yingtan & Ultisol & 2.93 & 5.94 & 5.83 & 5.89 & 1.79 & 248.5 & 5.02 \\
\hline Qiqihaer & Mollisol & 2.22 & 2.74 & 3.18 & 3.63 & 3.85 & 172.2 & 8.02 \\
\hline Wuhu & Alfisol & 2.06 & 4.96 & 4.80 & 4.85 & 3.34 & 390.7 & 5.93 \\
\hline Lanzhou & Aridisol & 2.49 & 3.79 & 4.53 & 4.83 & 2.13 & 102.4 & 7.51 \\
\hline Beijing & Alfisol & 7.46 & 8.95 & 5.84 & 8.31 & 3.11 & 335.8 & 7.37 \\
\hline Chendu & Inceptisol & 1.86 & 2.82 & 2.59 & 2.17 & 1.98 & 181.0 & 7.89 \\
\hline Tianjin & Alfisol & 4.53 & 3.23 & 3.19 & 3.13 & 3.05 & 159.2 & 7.75 \\
\hline Daxing & Alfisol & 2.55 & 2.93 & 2.45 & 2.58 & 2.56 & 129.2 & 7.88 \\
\hline Xiamen & Ultisol & 3.11 & 4.12 & 3.82 & 4.16 & 2.10 & 423.2 & 4.96 \\
\hline
\end{tabular}

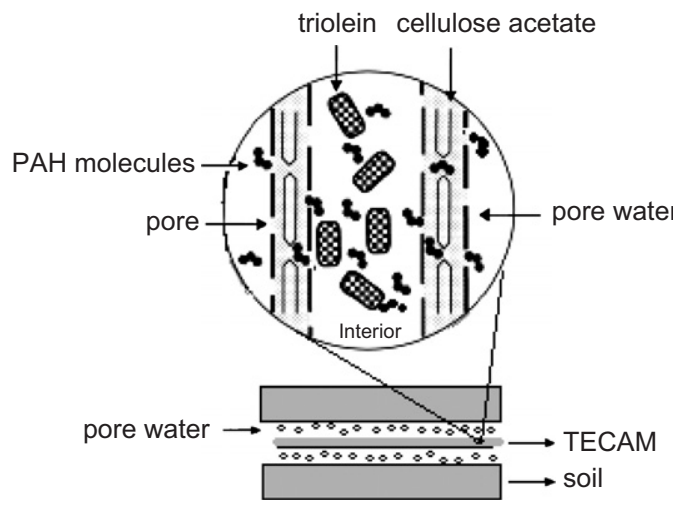

Fig. 1 - Schematic diagram of TECAM accumulation of PAHs from the soil.

beaker containing a $300 \mathrm{~g}$ soil subsample. Deionized water $(90 \mathrm{ml})$ was added dropwise to moisten the soil. The beakers were covered with moist filter paper and kept in the dark at 20-22 ${ }^{\circ} \mathrm{C}$. Earthworms were recovered after 21 days.

\subsection{Determination of PAHs in soil pore water}

Soil $(20 \mathrm{~g})$ and $6 \mathrm{ml}$ deionized water were added to a $50 \mathrm{ml}$ glass centrifuge tube which was kept in the dark at $20-22^{\circ} \mathrm{C}$ for $48 \mathrm{~h}$. Pore water was collected by centrifuging the mixture at $4000 \mathrm{~g}$ for $30 \mathrm{~min}$ and then filtering $(0.45 \mu \mathrm{m}$ pore size). Pore water $(5 \mathrm{ml})$ was extracted with $5 \mathrm{ml} n$-hexane three times. The organic phase was then dehydrated with anhydrous sodium sulfate and evaporated under a gentle nitrogen stream, solvent-exchanged into methanol $(1.00 \mathrm{ml})$ and stored prior to analysis.

\subsection{Chemical analysis}

Triplicate subsamples of each soil were collected and analyzed by the following steps. Each soil subsample $(2 \mathrm{~g})$ was thoroughly mixed with 6-7g anhydrous sodium sulfate, loaded into a Soxhlet thimble and extracted with $100 \mathrm{ml}$ $n$-hexane/dichloromethane $(1: 1 \mathrm{v} / \mathrm{v})$ at $60^{\circ} \mathrm{C}$ for $24 \mathrm{~h}$. The extract was reduced to about $5 \mathrm{ml}$ with a rotary evaporator, purged to about 1-2 $\mathrm{ml}$ under a gentle nitrogen stream and then cleaned with a $10 \mathrm{~g}$ neutral alumina/anhydrous sodium sulfate composite column and eluted with $60 \mathrm{ml} n$-hexane/ dichloromethane $(4: 1 \mathrm{v} / \mathrm{v})$. The eluates were finally evaporated, solvent-exchanged into methanol $(1.00 \mathrm{ml})$ and stored prior to analysis.

Earthworms were removed from the soils and allowed to depurate for $24 \mathrm{~h}$ to purge the gut contents on wet filter paper. They were then cleaned with deionized water to remove external soil particles, freeze dried, weighed and cut into small pieces that were mixed with $3-5 \mathrm{~g}$ anhydrous sodium sulfate and ground with a mortar and pestle to obtain homogeneous samples. Extraction and cleanup were the same as for soil as described above.

TECAM samples were rinsed with deionized water, wiped with clean filter paper, dialyzed in $20 \mathrm{ml} n$-hexane for $24 \mathrm{~h}$ and rinsed with $1 \mathrm{ml} n$-hexane three times. All the solutions were combined together. Dialysis solutions of TECAMs were evaporated under a gentle nitrogen stream, solvent-exchanged into methanol $(1.00 \mathrm{ml})$ and stored prior to analysis. TECAMs were stable in $n$-hexane with negligible weight loss of triolein or cellulose acetate during dialysis, and therefore no cleanup of the samples was required.

PAHs in samples were analyzed by HPLC-FLD (Agilent 1200 Series). Chromatographic separation and resolution were best achieved by using a Supelcosil (Supelco, Bellefonte, CA) LC$\mathrm{PAH}$ reverse-phase $\mathrm{C}_{18}$ column $(4.6 \times 150 \mathrm{~mm}, 5 \mu \mathrm{m}$ particle size) specific for PAH analysis. Samples were injected with a $20 \mu \mathrm{l}$ syringe, the injection volume was $20 \mu$ l, the mobile phase was methanol/water (0-11 $\mathrm{min}$, from $80 \% / 20 \%$ to $90 \% / 10 \%$; $11-18 \mathrm{~min}, 90 \% / 10 \%)$ and the $\mathrm{C}_{18}$ column was kept at $25^{\circ} \mathrm{C}$. The excitation wavelength of Nap, Phe, Pyr and BaP was $260 \mathrm{~nm}$. The emission wavelength of Nap and Phe was $350 \mathrm{~nm}$ and that of Pyr and BaP was $420 \mathrm{~nm}$.

Results were obtained from three replicates in the case of TECAMs and soils and from five replicates in the case of earthworms. Solvent, TECAM, soil and earthworm controls were included. Extraction recoveries of Nap, Phe, Pyr and BaP in TECAM were determined by adding the standard solution of these PAHs at seven different concentrations to a solvent 
mixture of acetone (69wt\%) and 1,4-dioxane (10wt\%) before TECAM preparation. The recoveries of Nap, Phe, Pyr and $\mathrm{BaP}$ were $75.2 \pm 2.1 \%, 83.7 \pm 1.9 \%, 89.4 \pm 2.7 \%$ and $93.5 \pm 2.8 \%$, respectively. Extraction recoveries of Nap, Phe, Pyr and $\mathrm{BaP}$ in soil were determined by adding standard solutions of PAHs at seven concentrations to the soil. The recoveries were $87.3 \pm 2.7 \%, 94.3 \pm 1.9 \%, 90.5 \pm 2.2 \%$ and $87.3 \pm 1.8 \%$.

\section{Results and discussion}

\subsection{Optimization of TECAM exposure conditions}

TECAMs accumulated the four PAHs in soil within $48 \mathrm{~h}$ (unpublished data), much more quickly than other PSDs composed of hydrophobic polymers or polyethylene films. The exposure time of 21 days was chosen in this study to maintain the same conditions as used for earthworms.

TECAMs of sizes $4,6,9,12$ and $16 \mathrm{~cm}^{2}$ were used to investigate the optimum TECAM size for accumulation of PAHs. The accumulation of each PAH in TECAM was positively related to the size of the TECAM. However, the concentration of each PAH ( $\mu \mathrm{gg}^{-1}$ TECAM) was almost constant (Fig. 2A) irrespective of the TECAM size and $6 \mathrm{~cm}^{2}$ TECAMs were used later in the study. The concentrations of Nap, Phe, Pyr and BaP in pore water were $87.8,14.0,5.17$ and $1.27 \mu \mathrm{gl}^{-1}$ and the volume of pore water was $3 \mathrm{ml}$ (water-to-soil ratio $30 \%$ ). The amounts of Nap, Phe, Pyr and $\mathrm{BaP}$ in pore water were therefore 263.3, 42.0, 15.5 and $3.81 \mathrm{ng}$, accounting for $0.45 \%$, $0.06 \%, 0.03 \%$ and $0.03 \%$ of the total amount of Nap, Phe, Pyr and $\mathrm{BaP}$ in the soil. The amounts of Nap, Phe, Pyr and BaP accumulated in the $6 \mathrm{~cm}^{2}$ TECAMs were 63.6, 104.1, 43.2 and $9.45 \mathrm{ng}$, accounting for $0.11 \%, 0.16 \%, 0.09 \%$ and $0.08 \%$ of the total amount of Nap, Phe, Pyr and BaP in the soil, values close to the fractions of PAHs in pore water. This suggests that the fraction of PAHs accumulated in TECAMs was the bioavailable fraction in the soil and therefore TECAMs have the potential to predict the bioavailability of PAHs in soils. In addition, only a small fraction of the total amount of PAHs in soil was present in pore water and transported to the membrane through aqueous pathways, and the amount of PAHs in the soil remained virtually unchanged after TECAMs were embedded in the soils. This suggests that TECAM sampling was virtually nondestructive and led to minimum disturbance of soils.

Five different water-to-soil ratios, namely $20 \%$, 30\%, 50\%, $100 \%$ and $200 \%$, were chosen to investigate the effect of soil moisture on the accumulation of PAHs by TECAM. The concentrations of Nap and Phe in TECAM increased as the ratio of water to soil increased from $20 \%$ to $200 \%$ (Fig. 2B). However, the concentrations of Pyr and BaP in TECAM did not change significantly. This may be due to differences in their aqueous solubility and ability to desorb from soil into pore water. The aqueous solubilities of Nap and Phe are 30.2 and $1.18 \mathrm{mgl}^{-1}$ (Petty et al., 1994) and their $\log K_{\text {ow }}$ values are 3.33 and 4.57 (Schwarzenbach, et al., 2003), respectively. They are not difficult to desorb from soil into pore water. In contrast, Pyr and $\mathrm{BaP}$ have low water solubilities (0.135 and $0.0038 \mathrm{mgl}^{-1}$ ) and high hydrophobicities ( $\log \mathrm{K}_{\mathrm{ow}}=5.13$ and 6.13). They tend to interact strongly with SOM and are difficult
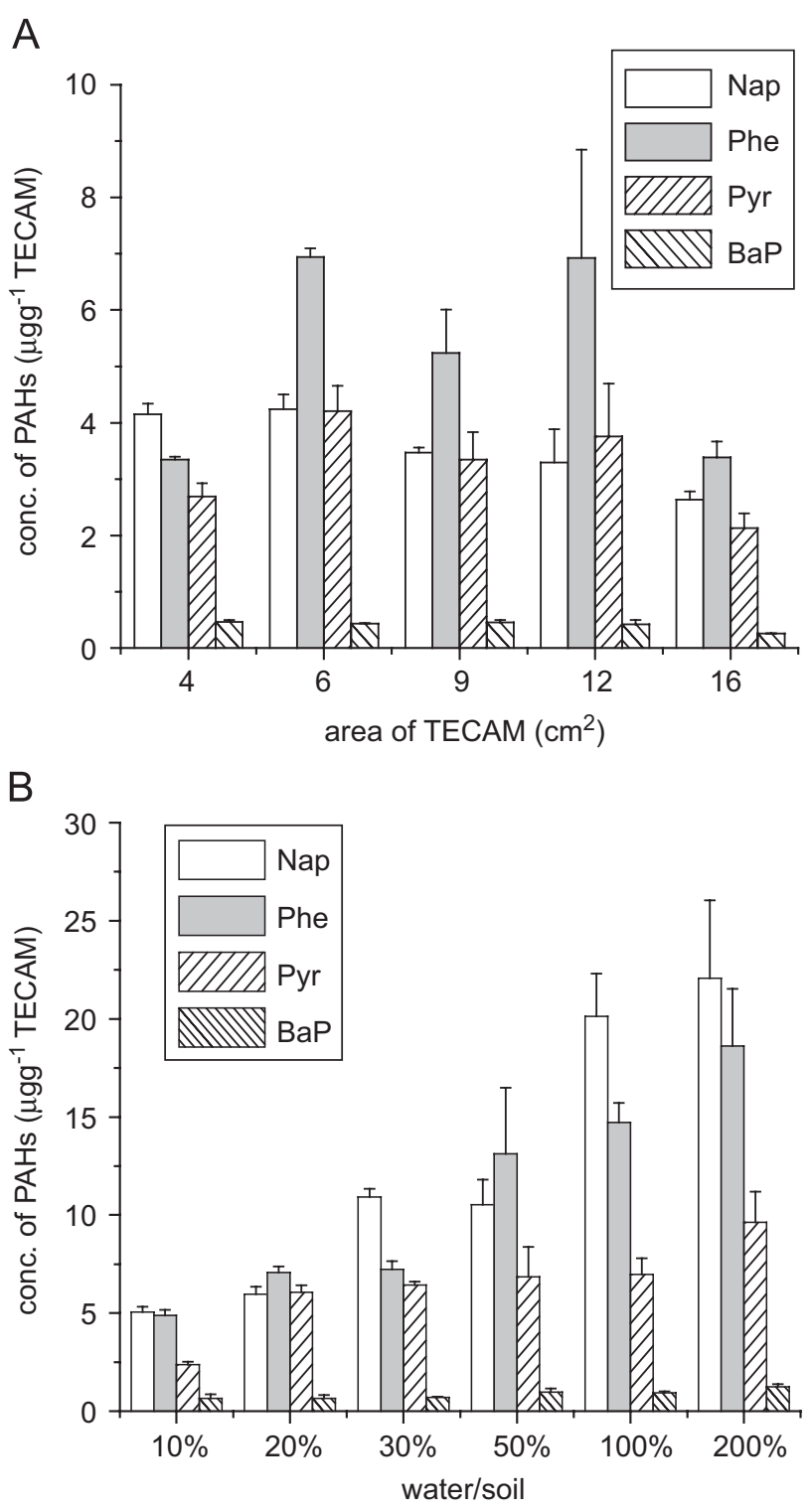

Fig. 2 - Relationship between PAH concentration in TECAMs and the size of TECAMs (A), and the ratio of water and soil (B).

to desorb from soil into pore water. Therefore, the dissolved amounts of Pyr and BaP in soil pore water increased slightly as the ratio of water to soil increased. A ratio of $30 \%$ was used in the later experiment because it is equivalent to a $60-70 \%$ of soil water holding capacity and matches with the field soil moisture content and the environmental conditions experienced by the earthworms.

\subsection{Relationship between accumulation of PAHs by TECAMs and PAH concentrations in the soil}

Beijing soil spiked with Nap, Phe, Pyr and BaP at initial concentrations of $0.2,0.5,2.0,5.0$ and $10.0 \mu \mathrm{gg}^{-1}$ after incubation for three months was used in this part of the study. TECAMs were embedded in the soil for 21 days. 
A strong linear relationship was found between the concentrations of PAHs accumulated by TECAMs ( $C_{\text {TECAM }}$ ) and concentrations of PAHs in the soil $\left(C_{\text {soil }}\right)$ (see Fig. 3$)$. The slope, referred to as the apparent partitioning coefficient ( $\left.K_{\text {TECAM }}\right)$ after 21 days, was $0.47,2.84,1.24$ and 0.33 for Nap, Phe, Pyr and BaP, respectively. No linear relationship existed between $\log K_{\text {TECAM }}$ and $\log K_{\text {ow }}$ of these four PAHs, with the maximum being observed for Phe $\left(\log K_{\text {ow }}=4.57\right)$ (Fig. $\left.4 \mathrm{~A}\right)$. This result agrees well with previous reports. Several authors (Gobas et al., 1989; Nendza, 1991; Verhaar et al., 1999) have observed that at low and intermediate $\log K_{\text {ow }}$ there seems to be a linear relationship between $\log$ BCF (bioconcentration factor) and $\log K_{\mathrm{ow}}$, while at high $\log \mathrm{K}_{\mathrm{ow}}$ deviations were seen, generally indicating that for these compounds BCF increases less than proportionally with increasing $\log \mathrm{K}_{\mathrm{ow}}$. However, a significant linear relationship $\left(R^{2}=0.998, P<0.01\right)$ was found between $\log K_{\text {TECAM-W }}$ (the partition coefficient of PAHs between TECAM and water) and $\log K_{\text {ow }}$ (Fig. 4B). The likely explanation for the decline in accumulation from soil by TECAMs for the PAHs with higher $\log K_{\text {ow }}$ is as follows. The uptake rate of HOCs to PSDs was controlled mainly by the membrane and aqueous boundary layer (Booij et al., 2003). Resistance posed by the aqueous boundary layer may have been reduced as a result of chemical desorption from the particles near the membrane surface. However, PAHs with high $\log K_{\text {ow }}$ values could interact strongly with soil organic matter (SOM) due to their high hydrophobicity, resulting in their strong sequestration in soil and resistance to desorption. Furthermore, nanopores or voids are abundant in the organic fraction of soils (Malekani et al., 1997; White et al.,
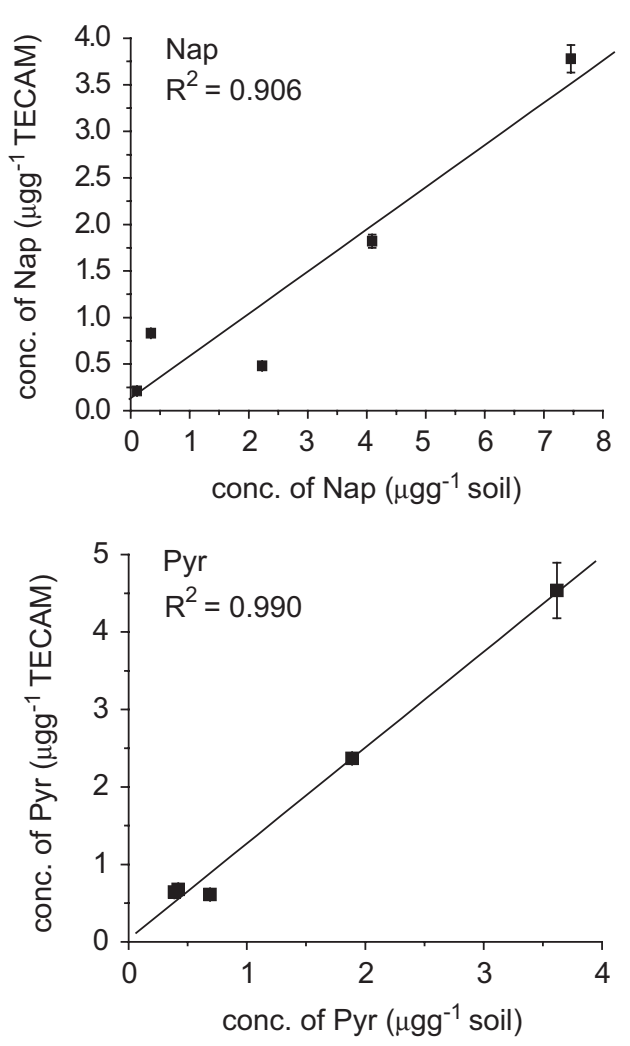
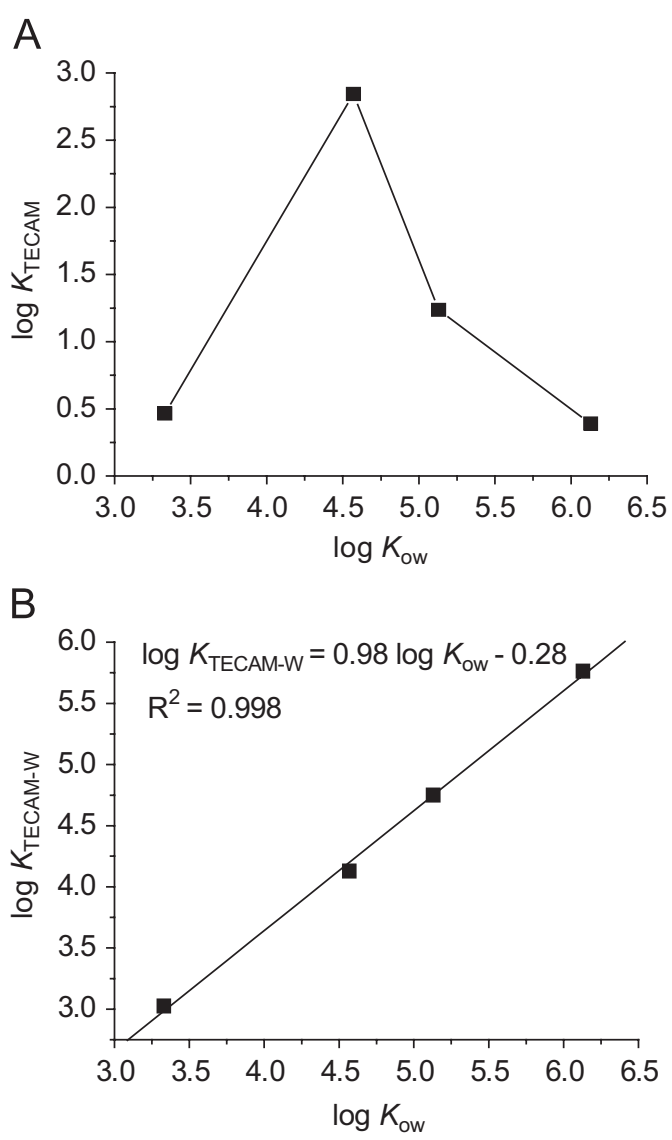

Fig. 4 - Correlations between $K_{\text {TECAM }}$ and $K_{\text {ow }}(A)$, and $K_{\text {TECAM-W }}$ and $K_{\text {ow }}(B)$.


Fig. 3 - Relationship between PAH accumulation in TECAMs and the concentrations in the soil. 
1998). PAHs with higher $\log K_{\text {ow }}$ usually have larger molecular volumes. If the molecules were entrapped in such pores or voids they would tend not to escape and would become nonbioavailable. PAHs with higher $\log K_{\text {ow }}$ may therefore show greater resistance posed by the aqueous boundary layer, resulting in lower accumulation in TECAMs.

\subsection{Effect of soil characteristics on accumulation of PAHs by TECAMs}

TECAMs were exposed to ten soils spiked with $5 \mu \mathrm{gg}^{-1} \mathrm{Nap}$, Phe, Pyr and BaP after incubation for three months. Relationships between the concentrations of PAHs accumulated by TECAMs and the contents of SOM and dissolved organic carbon (DOC) were investigated. There was a negative correlation between PAHs in TECAMs and SOM (Fig. 5A). This trend would be expected because PAHs may interact with SOM or be entrapped into macromolecular structures, nanopores or voids of SOM. This fraction of PAHs is hard to desorb into soil pore water, resulting in lower equilibrium concentrations of PAHs in pore water. A positive correlation was observed between PAHs in TECAMs and DOC (Fig. 5B). Similar relationships were reported by Tao et al. (2006), when they analyzed the concentrations of PAHs accumulated by wheat (Triticum aestivum L.), SOM and DOC in soils. Kukkonen and Oikari (1991) provided very clear evidence of the enhancement of bioavailability of organic compounds. They found that ten natural water samples with DOC concentrations below approximately $10 \mathrm{mgl}^{-1}$ enhanced the uptake of naphthalene into D. magna. Muir et al. (1994) also found a marked enhancement of bioconcentration for the uptake of pyrethroids into rainbow trout. Haitzer et al. (1998) also reviewed enhancement of the bioavailability of organic compounds due to low concentrations of DOC $\left(<10 \mathrm{mgl}^{-1}\right)$ in natural waters. However, the mechanism remained obscure. In the present study the DOC of the 10 soils varied from 102.4 to $423.2 \mu^{-1} g^{-1}$, but we also observed a positive correlation between PAHs in TECAMs and DOC. There is still no information on enhancement of bioavailability of organic compounds taken up by PSDs due to DOC in soil pore water. DOC may enhance the kinetics of desorption or transport of PAHs in soils, and the desorption of DOC-bound PAHs near the TECAM surface would reduce the resistance posed by the aqueous boundary layer, leading to an increase in uptake rate and an extra flux to TECAMs, resulting in an enhancement of bioavailability of PAH accumulation in TECAMs.

\subsection{Effect of aging on accumulation of PAHs by TECAMs}

Previous laboratory and field studies have shown that aging of chemicals in soil has led to a diminished bioavailability to microorganisms (Steinberg et al., 1987), earthworms (Morrison et al., 2000) and plants (Führ and Mittelstaedt, 1980). A number of studies have investigated the aging of PAHs in soils or sediments by determining their extractability with solvents. However, there is no published information on
A
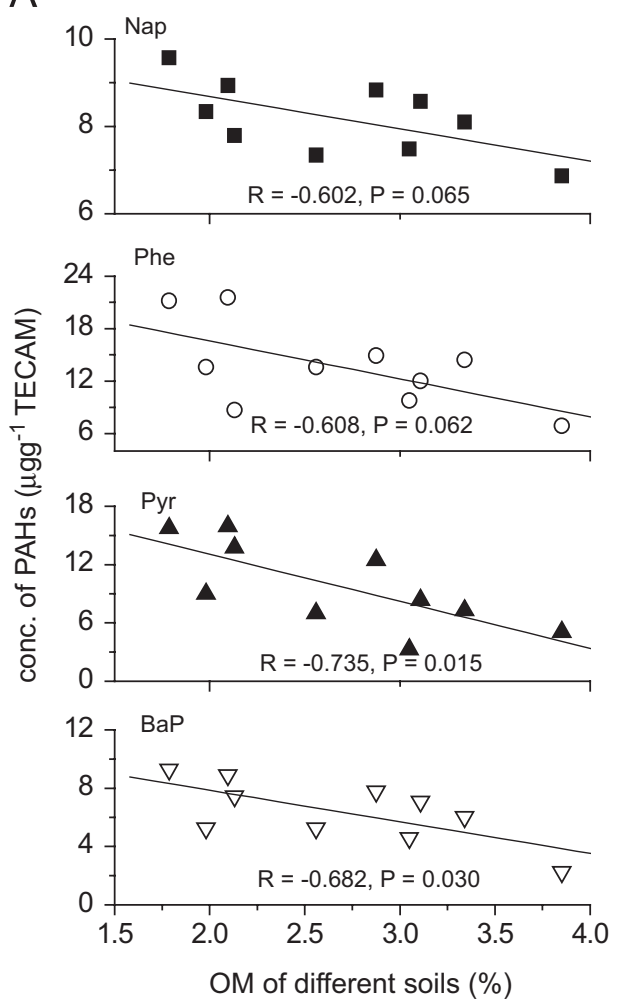

B
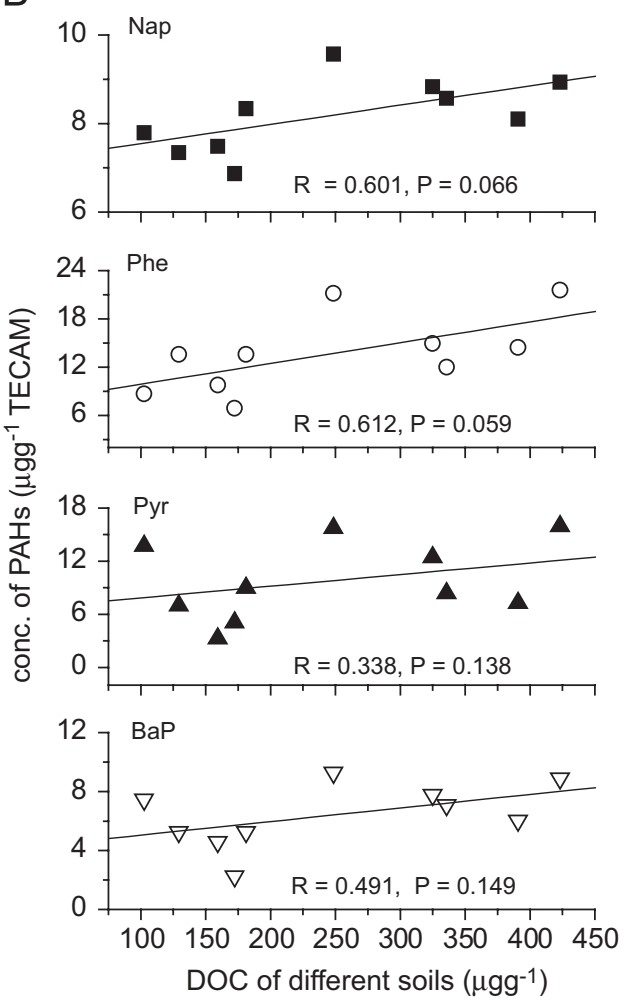

Fig. 5 - Relationship between PAHs accumulated by TECAMs and SOM and DOC of ten different soils. 
the use of PSDs to estimate aging effects on bioavailability of HOCs in soils. To evaluate the effect of aging on Nap, Phe, Pyr and $\mathrm{BaP}$ accumulation in TECAMs, Beijing soil was spiked with $5 \mu \mathrm{g} \mathrm{g}^{-1}$ Nap, Phe, Pyr and BaP and aged for 1, 3, 15, 60, 90, 120 and 150 days. The concentrations of the PAHs in the soil changed less than $10 \%$ during this aging period. Accumulation of PAHs by TECAMs was plotted against aging time (Fig. 6) and this showed that aging had a significant effect on accumulation of PAHs by TECAMs. A biphasic accumulation pattern was observed for Nap, Phe and Pyr with an initial rapid decrease followed by a slower decline. In contrast, this pattern was not observed for BaP, and this may be attributed to its higher rate of sorption to the soil and stronger

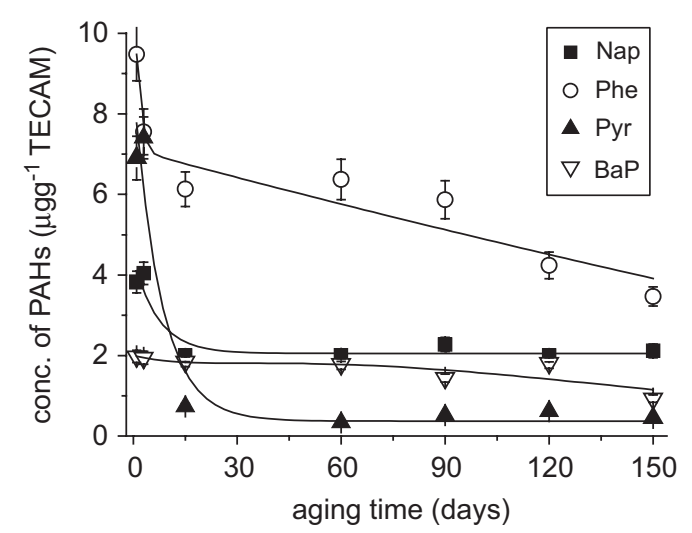

Fig. 6 - Effect of aging on PAHs accumulated by TECAMs.
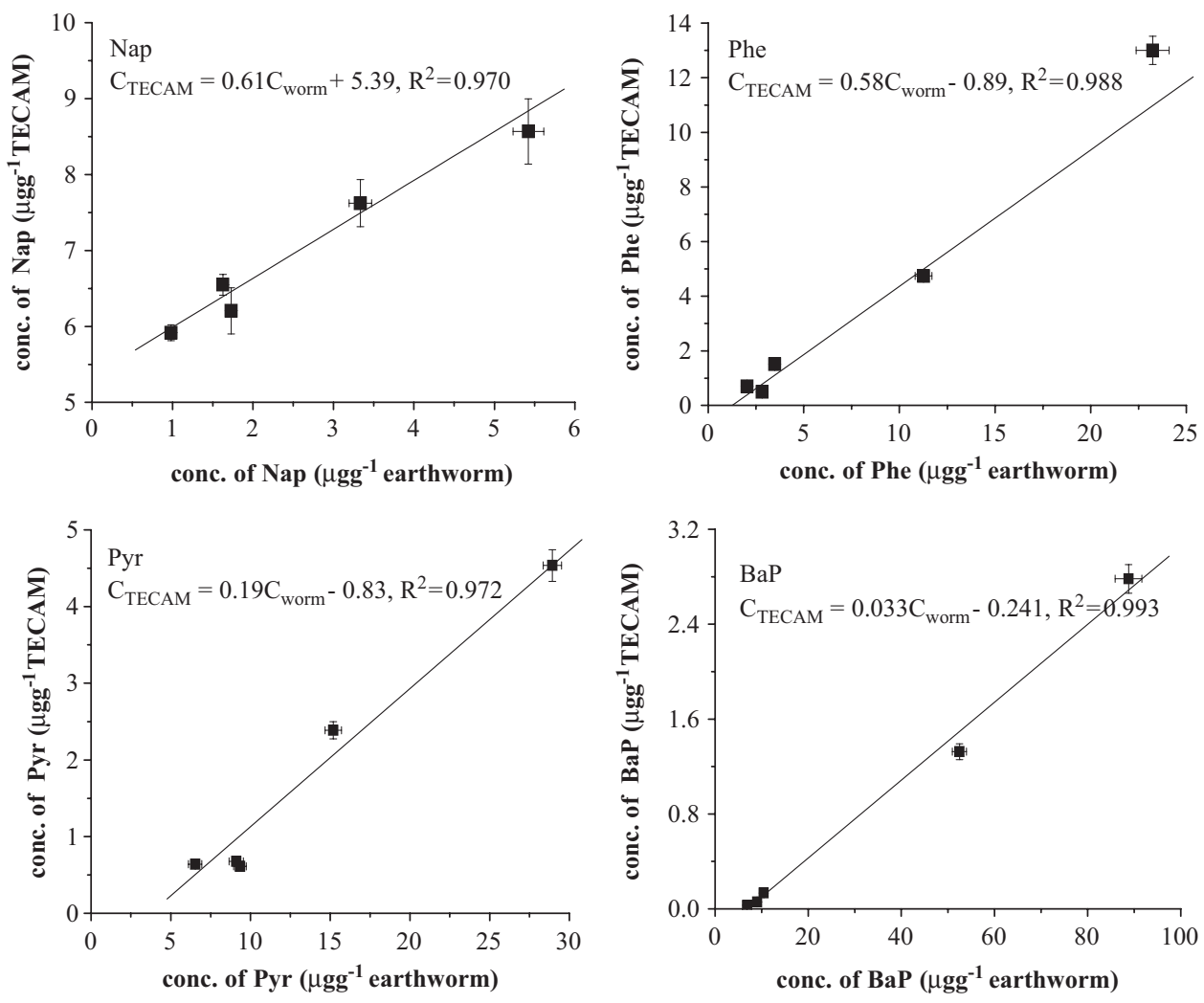

Fig. 7 - Relationship between PAHs accumulated by TECAMs and earthworms $(n=5)$. 
through dermis and digestion of particle-associated contaminants in soil (Belfroid et al., 1996). The first route is similar to the uptake by TECAMs and freely dissolved PAHs in soil pore water are accumulated mainly by passive diffusion. The second route leads to the diffusion of the contaminants across the gastrointestinal tract and accumulation in the earthworm tissues (Krauss et al., 2000). Activities of earthworms such as creeping, digging holes and excretion may also result in local disturbance of soil and the dissolution of a fraction of particle-associated PAHs into soil pore water. However, TECAMs were gently embedded in the soils. Pyr and $\mathrm{BaP}$ have stronger interaction with SOM due to their higher hydrophobicity, leading to a low concentration in soil pore water and a lower bioavailability to TECAMs. On other hand, due to their higher hydrophobicity, Pyr and BaP tend to bind strongly to tissues, resulting in their higher accumulation in earthworms. Nevertheless, very good linear relationships existed between the accumulation of PAHs in TECAMs and earthworms, suggesting that TECAMs may be useful as a surrogate to estimate the bioavailability of PAHs in soils.

\section{Conclusions}

The present study has indicated that TECAMs can efficiently and quickly accumulate PAHs from spiked soils and that TECAMs are sensitive to the concentrations of PAHs in soils, to soil characteristics and to the aging time of the PAHs. Laboratory preparation of TECAMs is easy and the accumulation process is also simple and requires no cleanup step. We therefore conclude that TECAM represents a useful surrogate to estimate the bioavailability of PAHs and perhaps other HOCs in soils. However, further research will be required to test their applicability under field conditions or for other compounds.

\section{Acknowledgments}

This work was funded by the National Natural Science Foundation of China (Project 20621703 and 4073xxx) and the Hi-tech Research and Development Program of China.

R E F E R E N C E S

Ahn, S., Werner, D., Luthy, R.G., 2005. Physicochemical characterization of coke-plant soil for the assessment of polycyclic aromatic hydrocarbon availability and the feasibility of phytoremediation. Environ. Toxicol. Chem. 24, 2185-2195.

Alexander, M., 1995. How toxic are toxic chemicals in soil? Environ. Sci. Technol. 29, 2713-2717.

Alexander, M., 2000. Aging, bioavailability, and overestimation of risk from environmental pollutants. Environ. Sci. Technol. 34, 4259-4265.

Awata, H., Cobb, G.P., Anderson, T.A., 2000. A chemical test for determining biological availability of aged chemicals in soil. Int. J. Environ. Anal. Chem. 78, 41-49.

Belfroid, A.C., Sijm, D.T.H.M., Van Gestel, C.A.M., 1996. Bioavailability and toxicokinetics of hydrophobic aromatic compounds in benthic and terrestrial invertebrates. Environ. Rev. 4, 276-299.
Booij, K., Hoedemaker, J.R., Bakker, J.F., 2003. Dissolved PCBs, PAHs and HCB in pore waters and overlying waters of contaminated harbor sediments. Environ. Sci. Technol. 37, 4213-4220.

Conder, J.M., La Point, T.W., Lotufo, G.R., Steevens, J.A., 2003. Nondestructive, minimal-disturbance, direct-burial solidphase microextraction fiber technique for measuring TNT in sediment. Environ. Sci. Technol. 37, 1625-1632.

Führ, F., Mittelstaedt, W., 1980. Plant experiments on the bioavailability of unextracted [carbonyl- ${ }^{14} \mathrm{C}$ ] methabenzthiazuron residues from soil. J. Agric. Food Chem. 28, 122-125.

Gobas, F.A.P.C., Clark, K.E., Shiu, W.Y., Mackay, D., 1989. Bioconcentration of polybrominated benzenes and biphenyls and related superhydrophobic chemicals in fish: elimination into the feces. Environ. Toxicol. Chem. 8, 231-245.

Gourlay, C., Miege, C., Noir, A., Ravelet, C., Garric, J., Mouchel, J., 2005. How accurately do semi-permeable membrane devices measure the bioavailability of polycyclic aromatic hydrocarbons to Daphnia magna? Chemosphere 61, 1734-1739.

Haitzer, M., HÖss, S., Traunspurger, W., Steinberg, C., 1998. Effects of dissolved organic matter (DOM) on the bioconcentration of organic chemicals in aquatic organisms-a review. Chemosphere 37, 1335-1362.

Hernandez, F., Beltran, J., Lopez, F.J., Gaspar, J.V., 2000. Use of solidphase microextraction for the quantitative determination of herbicides in soil and water samples. Anal. Chem. 72, 2313-2322.

Huckins, J.N., Tubergen, M.W., Manuweera, G.K., 1990. Semipermeable membrane devices containing model lipid: a new approach to monitoring the bioavailability of lipophilic contaminants and estimating their bioconcentration potential. Chemosphere 20, 533-552.

Huckins, J.N., Petty, J.D., Orazio, C.E., Lebo, J.A., Clark, R.C., Gibson, V.L., Gala, W.R., Echols, K.R., 1999. Determination of uptake kinetics (sampling rates) by lipid-containing semipermeable membrane devices (SPMDs) for polycyclic aromatic hydrocarbons (PAHs) in water. Environ. Sci. Technol. 33, 3918-3923.

Ke, R., Xu, Y., Wang, Z., Khan, S., 2006. Estimation of the uptake rate constants for polycyclic aromatic hydrocarbons accumulated by semipermeable membrane devices and trioleinembedded cellulose acetate membranes. Environ. Sci. Technol. 40, 3906-3911.

Kelsey, J.W., Kottler, B.D., Alexander, M., 1997. Selective chemical extractants to predict bioavailability of soil-aged organic chemicals. Environ. Sci. Technol. 31, 214-217.

Krauss, M., Wilcke, W., Zech, W., 2000. Availability of polycyclic aromatic hydrocarbons (PAHs) and polychlorinated biphenyls (PCBs) to earthworms in urban soils. Environ. Sci. Technol. 34, 4335-4340.

Krauss, M., Wilcke, W.G., 2001. Biomimetic extraction of PAHs and PCBs from soil with octadecyl-modified silica disks to predict their availability to earthworms. Environ. Sci. Technol. 35, 3931-3935.

Kukkonen, J., Oikari, A., 1991. Bioavailability of organic pollutants in boreal waters with varying levels of dissolved organic material. Water Res. 25, 455-463.

Malekani, K., Rice, J.A., Lin, J.S., 1997. The effect of sequential removal of organic matter on the surface morphology of humin. Soil Sci. 162, 333-342.

Morrison, D.E., Robertson, B.K., Alexander, M., 2000. Bioavailability to earthworms of aged DDT, DDE, DDD, and dieldrin in soil. Environ. Sci. Technol. 34, 709-713.

Muir, D.C.G., Hobden, B.R., Servos, M.R., 1994. Bioconcentration of pyrethroid insecticides and DDT by rainbow trout: uptake, depuration, and effect of dissolved organic carbon. Aquat. Toxicol. 29, 230-240.

Nelson, D.W., Sommers, L.E., 1982. Total carbon, organic carbon and organic matter. In: Page, A.L., Miller, R.H., Keeney, D.R. 
(Eds.), Methods of Soil Analysis, Part 2. American Society of Agronomy, Madison, WI, pp. 539-579.

Nendza, M., 1991. Predictive QSAR models estimating ecotoxic hazard of phenylureas: mammalian toxicity. Chemosphere 22, 613-623.

Petty, J.D., Huckins, J.N., Orazio, C.E., Lebo, J.A., Clark, R.C., Gibson, V.L., 1994. Laboratory studies of the use of semipermeable membrane devices (SPMDs) as passive water samplers of polyaromatic hydrocarbon (PAH) priority pollutants. Final Report no. 93-045. National Biological Survey, Columbia, MO.

Rantalainen, A.L., Passivirta, J., Herve, S., 1998. Uptake of chlorohydrocarbons from soil by lipid-containing semipermeable membrane devices (SPMDs). Chemosphere 36, 1415-1427.

Rantalainen, A.L., Cretney, W.J., Ikonomou, M.G., 2000. Uptake rates of semipermeable membrane devices (SPMDs) for PCDD, PCDFs and PCBs in water and sediment. Chemosphere 40, 147-158.

Reid, B.J., Jones, K.C., Semple, K.T., 2000a. Bioavailability of persistent organic pollutants in soils and sediments-a perspective on mechanisms, consequences and assessment. Environ. Pollut. 108, 103-112.

Reid, B.J., Stokes, J.D., Jones, K.C., Semple, K.T., 2000b. Nonexhaustive cyclodextrin-based extraction technique for the evaluation of PAH bioavailability. Environ. Sci. Technol. 34, 3174-3179.

Schwarzenbach, R.P., Gschwend, P.M., Imboden, D.M., 2003. Environ. Org. Chem., second ed. Wiley, New York.

Semple, K.T., Morriss, A.W.J., Paton, G.I., 2003. Bioavailability of hydrophobic organic contaminants in soils: fundamental concepts and technique for analysis. Eur. J. Soil Sci. 54, 809-818.

Söderström, H., Hajšlová, J., Kocourek, V., Siegmund, B., Kocan, A., Obiedzinski, M.W., Tysklind, M., Bergqvist, P., 2005. PAHs and nitrated PAHs in air of five European countries determined using SPMDs as passive samplers. Atmos. Environ. 39, 1627-1640.
Steinberg, S.M., Pignatello, J.J., Sawhney, B.L., 1987. Persistence of 1,2-dibromoethane in soils: entrapment in intraparticle micropores. Environ. Sci. Technol. 21, 1201-1208.

Tang, J., Liste, H., Alexander, M., 2002. Chemical assays of availability to earthworms of polycyclic aromatic hydrocarbons in soil. Chemosphere 48, 35-42.

Tao, S., Xu, F., Liu, W., Cui, Y., Coveney, R.M., 2006. A chemical extraction method for mimicking bioavailability of polycyclic aromatic hydrocarbons to wheat grown in soils containing various amounts of organic matter. Environ. Sci. Technol. 40, 2219-2224.

Van Der Wal, L., Jager, T., Fleuren, R.H.L.J., Barendregt, A., Sinnige, T.L., Van Gestel, C.A.M., Hermens, J.L.M., 2004. Solidphase microextraction to predict bioavailability and accumulation of organic micropollutants in terrestrial organisms after exposure to a field-contaminated soil. Environ. Sci. Technol. $38,4842-4848$

Verhaar, H.J.M., Busser, F.J.M., Hermens, J.L.M., 1995. A surrogate parameter for the baseline toxicity content of contaminated water: simulating the bioconcentration of unknown mixtures and counting their molecules. Environ. Sci. Technol. 29, 726-734.

Verhaar, H.J.M., Jongh, J.D., Hermens, J.L.M., 1999. Modeling the bioconcentration of organic compounds by fish: a novel approach. Environ. Sci. Technol. 33, 4069-4072.

Verweij, F., Booij, K., Satumalay, K., Van Der Molen, N., Van Der Oost, R., 2004. Assessment of bioavailable PAH, PCB and OCP concentrations in water, using semipermeable membrane devices (SPMDs), sediments and caged carp. Chemosphere 54, 1675-1689.

White, J.C., Ravikovitch, P.I., Russo, R., Neimark, A., Pignatello, J.J., 1998. In: 1996-1998 Bioremediation Research Program Review; EPA/600/R-89/122. US Environmental Protection Agency, Washington, DC, pp. 19-20.

Xu, Y., Wang, Z., Ke, R., Khan, S., 2005. Accumulation of organochlorine pesticides from water using triolein embedded cellulose acetate membranes. Environ. Sci. Technol. 39, 1152-1157. 